\title{
Radiological and Surgical Anatomy of Ventral C1-C2 Complex
}

\author{
Sibel CIRPAN ${ }^{1}$, Salih SAYHAN ${ }^{1,2}$, Goksin Nilufer YONGUC ${ }^{1}$, Canan EYUBOGLU ${ }^{1}$, Nuri KARABAY ${ }^{3}$, \\ Mustafa GUVENCER ${ }^{1}$, Sait NADERI ${ }^{4}$ \\ 'Dokuz Eylul University, School of Medicine, Department of Anatomy, Izmir, Turkey \\ ${ }^{2}$ Private Medigunes Hospital, Neurosurgery Clinic, Manisa, Turkey \\ ${ }^{3}$ Dokuz Eylul University, School of Medicine, Department of Radiodiagnostics, Izmir, Turkey \\ ${ }^{4}$ Health Sciences University, Umraniye Education and Research Hospital, Department of Neurosurgery, Istanbul, Turkey
}

Corresponding author: Mustafa GUVENCER mustafa.guvencer@gmail.com

\section{ABSTRACT}

AIM: To evaluate anatomical data of the bony structures during exploration of the C1-C2 complex.

MATERIAL and METHODS: This study included six formalin-fixed cadaveric head and neck specimens. Radiological images and anatomical measurements included: $\mathrm{C} 1-\mathrm{C} 2$ distance, bony distance between $\mathrm{C} 1$ anterior tubercle-nares and superior incisors, height of $\mathrm{C} 1$ anterior arch, and height and width of odontoid articular surface.

RESULTS: The mean distance between C1 anterior tubercle-nares and superior incisors on maxilla were $96.16 \pm 8.07 \mathrm{~mm}$ and $84.14 \pm 9.16 \mathrm{~mm}$, respectively. The mean height of C1 anterior arch was $13.89 \mathrm{~mm}$. The meandistance between medial borders of right-left C1 lateral masses was $19.10 \pm 1.80 \mathrm{~mm}$. The mean distance between medial border of lateral midline on mass right and left sides were $9.43 \pm 0.88 \mathrm{~mm}$ and $9.68 \pm 0.97 \mathrm{~mm}$, respectively. The mean height of $\mathrm{C} 1$ anterior arch at midline was $13.89 \pm 2.48$ $\mathrm{mm}$, and the mean distance between ventral surface of anterior arch and ventral joint of odontoid at midline was $6.43 \pm 1.29 \mathrm{~mm}$. The anteroposterior, horizontal diameters of odontoid on its base were $12.12 \pm 0.38 \mathrm{~mm}$, and $11.12 \pm 0.94 \mathrm{~mm}$, respectively. The angles of transoral and transnasal approaches to $\mathrm{C} 1$ were $32.67 \pm 4.59^{\circ}$ and $32.00 \pm 2.10^{\circ}$, respectively.

CONCLUSION: A safe transoral or transnasal odontoidectomy requires accurate measurements and imaging regarding ventral C1C2 relationships, distances of odontoid, lateral mass and midline.

KEYWORDS: Atlantoaxial complex, Radiological anatomy, Surgical anatomy, Odontoidectomy, Cadaveric study

ABBREVIATIONS: C0-C1-C2: Occipito-atlanto-axial complex, C1: First cervical vertebra, C2: Second cervical vertebra, CT: Computed tomography, CVJ: Craniovertebral junction, FOV: Field of view, ML: Midline, TO: Transoral, TN: Transnasal

\section{INTRODUCTION}

$\mathrm{T}$ The transoral (TO) approach is an important route to reach to the upper cervical spine. This approach is commonly used for decompression of the craniovertebral junction (CVJ) ventrally, particularly for decompression of the upper cervical spinal cord due to cranial settling of the odontoid, CVJ tumours and infections. This route has also been used occasionally for $\mathrm{C} 0-\mathrm{C} 1-\mathrm{C} 2$ (occipito-atlanto-axial complex) ventral plating. Although the TO approach to the CVJ is an effective and important approach, it is associated with a high rate of morbidity. Therefore, many surgeons have recently started to perform minimally-invasive transnasal (TN) endoscopic odontoidectomy. Both TO and TN approaches require information about bony and neurovascular structures. The aim of this study is to measure bony structures related to these approaches after anterior exploration of the C1 (first cervical vertebra)-C2 (second cervical vertebra) complex.
Sibel CIRPAN $\quad$ (D) : 0000-0002-0654-9139

Salih SAYHAN (D) : 0000-0003-3594-8937

Goksin Nilufer YONGUC (D) : 0000-0002-6300-5365
Canan EYUBOGLU (D): 0000-0001-9833-6263

Nuri KARABAY (D) : 0000-0002-1059-5517

Mustafa GUVENCER (D) : 0000-0001-6953-2898
Sait NADERI (D) : 0000-0002-6784-4270 


\section{MATERIAL and METHODS}

This study was conducted at the Department of Anatomy of the Dokuz Eylul University School of Medicine. Permission for this investigation was obtained from the Dokuz Eylul University School of Medicine. Six adult head and neck cadaveric specimens fixed in formalin were used. The arteries and veins were filled with coloured silicon. The first component of the study was radiological imaging and measurement, and the second part included exploration of the surgical anatomy.

\section{Measurements on Radiological Images of Cadavers}

Computed tomography (CT) examination of the CVJ was performed before odontoidectomy. All CT examinations were performed with an 80-row detector CT scanner (Aquilion Prime; Toshiba). The study was conducted according to the following parameters: 120 peak kilovoltage (kVp); 80-120 milliamperes per second (mAs; $0.4 \mathrm{~s}$ gantry rotation period); 0.5-mm slice thickness; $512 \times 512$ matrix; and a 180-240 field of view (FOV). Three-dimensional measurements were made using the Vitrea workstation (Toshiba). The measurements were made on a sagittal image, while coronal and axial images were used for guidance. The radiological parameters are shown in Figure 1A, B.

Measurements of angles and distances related to TN and TO approaches are shown in Figure 2. The approach angles used a single entry point. For the TN approach, the entry point was defined as a point in the midline $(\mathrm{ML})$ at the inferior edge of the nasal bone. The most superior access within the surgical field was arbitrarily defined as the point on the clivus at the base of the sella. The most inferior access within the surgical field was then approximated by creating a straight line from the inferior

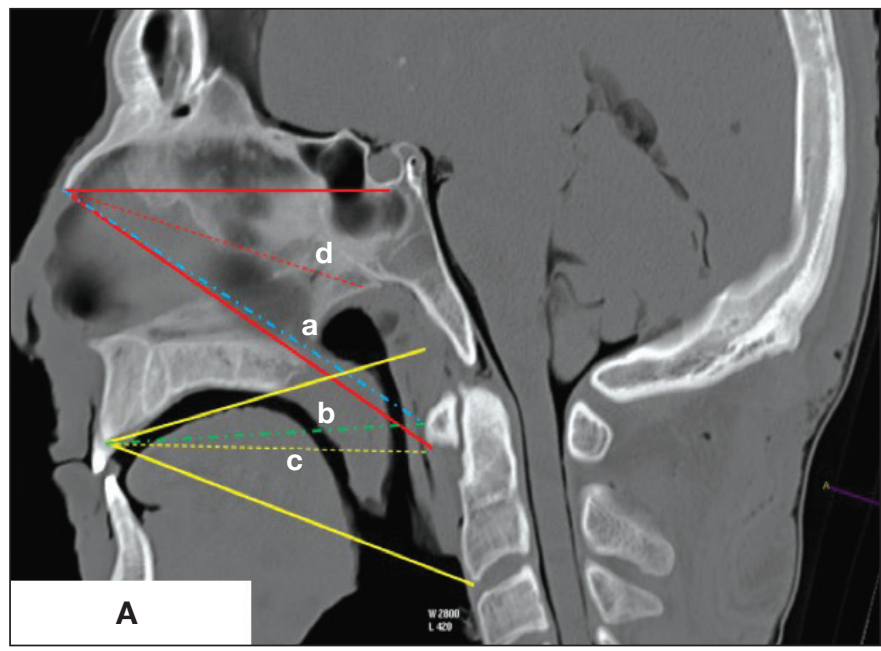

$M L$ of the nasal bone to the lowest point on the odontoid or C2 while remaining tangential to, but not crossing, the hard palate. For the TO approach, the entry point was defined as a point in the $\mathrm{ML}$ at the inferior edge of the superior incisors. The most superior access within the surgical field was defined as the point in the ML at the superior aspect of the lower third of the clivus. This was chosen as the point of superior access that did not split the soft palate based on anatomical dissections. The most inferior access within the surgical field was chosen as the inferoposterior aspect of the body of C2. The measured parameters are listed in Table I.

\section{Measurements on Cadavers During Surgical Dissection}

A TO odontoidectomy procedure was simulated. After exploration of the anterior $\mathrm{C} 1-\mathrm{C} 2$ through the TO route, the pharyngeal mucosa was opened, dissection of mucosa over the $\mathrm{C} 1$ and $\mathrm{C} 2$ was achieved, and the anterior arch of $\mathrm{C} 1$ was cut on both sides, just medial of the $\mathrm{C} 1$ lateral masses. After removal of the $\mathrm{C} 1$ anterior arch, the base of the odontoid process was cut and pulled out and downward. After cutting the apical and alar ligaments, the odontoid process was removed.

All structures were measured before or after odontoidectomy. The parameters related to surgical anatomy included the TN and TO approaches (Figure 2), lateral mass (Figure 3), and C1C2 ML (Figure 4A, B). The measured parameters are listed in Table II. The measurements were performed using a digital caliper sensitive to $0.01 \mathrm{~mm}$ (Mitotoyo).

The statistical analysis was performed using SPSS 22.0 (SPSS Inc., Chicago, IL, USA). Wilcoxon signed-rank test was used to evaluate the data, and $\mathrm{p} \leq 0.05$ was considered statistically significant.

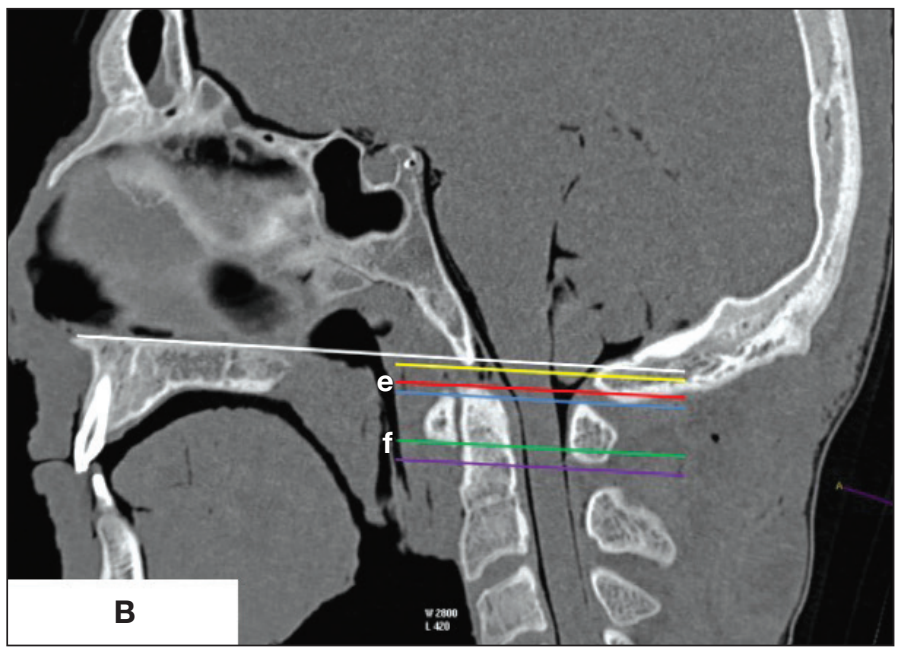

Figure 1: Radiological parameters. The built-in linear tool was used for measurements.

A) Red dotted line = TN approach angle (d), blue dotted line = TN approach distance (distance between the inferior edge of the nasal bone and the anterior aspect of the $\mathrm{C} 1 \mathrm{arch}$ ) (a), yellow dotted line = TO approach angle (c), green dotted line = TO approach distance (distance between the inferior edge of the superior incisors and the anterior aspect of the $\mathrm{C} 1 \mathrm{arch}$ ) (b).

B) Red line = odontoid tip level, blue line = superior aspect of the C1 arch, green line = inferior aspect of the C1 arch, purple line = odontoid base level. Inferior aspect of the $\mathrm{C} 1$ arch was measured relative to the odontoid base level. Distance between the red and blue lines = distance between a horizontal line drawn parallel to the superior edge of the C1 anterior arch and the odontoid apex (e), Distance between the purple and green lines = distance between a horizontal line drawn parallel to the inferior edge of the C1 anterior arch and the odontoid base (f). 
Table I: Parameters Measured on Radiological Images of Cadavers

The distance between anterior tubercle of $\mathrm{C} 1$ and nasal bone (a) (Figure 1A).

The distance between anterior tubercle of $\mathrm{C} 1$ and superior incisors on maxilla (b) (Figure 1A).

The angle of transoral approach to $\mathrm{C} 1$ (c) (Figure 1A).

The angle of transnasal approach to C1 (d) (Figure 1A).

The distance between horizontal line drawn parallel to superior edge of $\mathrm{C} 1$ anterior arch and odontoid apex in midsagittal view of the CT (e) (Figure 1B).

The distance between horizontal line drawn parallel to inferior edge of $\mathrm{C} 1$ anterior arch and odontoid base in midsagittal view of the CT (f) (Figure 1B).

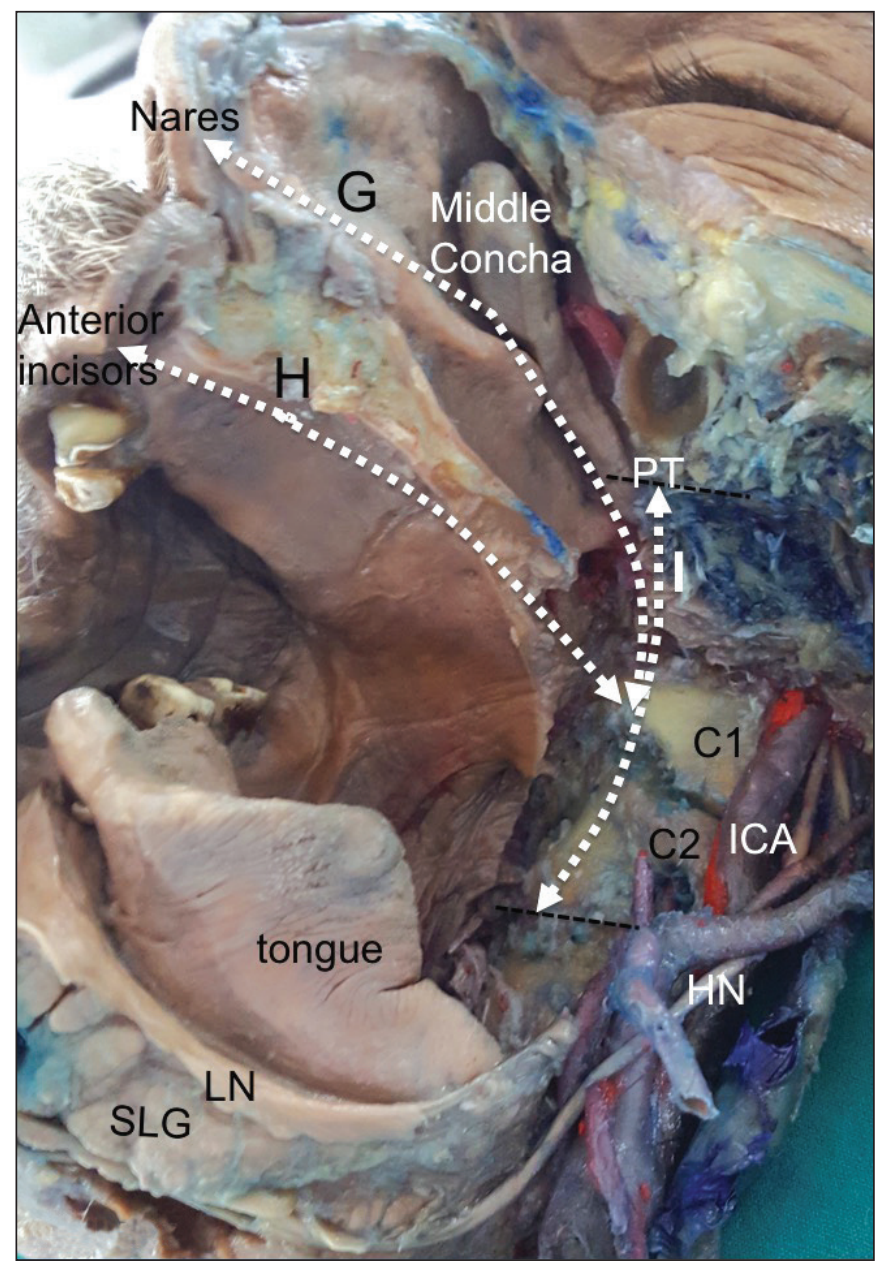

Figure 2: Parameters related to approach. ICA: Internal carotid artery; HN: hypoglossal nerve; PT: pharyngeal tubercle; SLG: sublingual gland, distance between nares and C1 anterior tubercle (G); distance between the superior incisors and the $\mathrm{C} 1$ anterior tubercle $\mathbf{( H )}$, distance between the pharyngeal tubercle and the inferior border of C2 body (I).

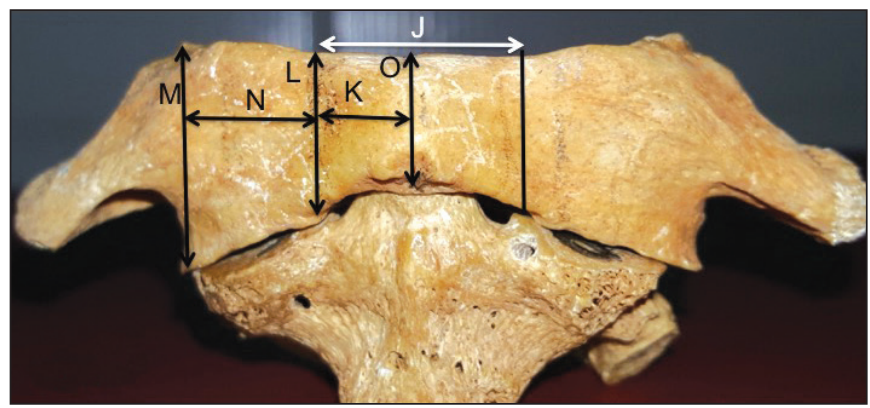

Figure 3: Ventrolateral parameters related to the lateral mass. Distance between the medial borders of right and left $\mathrm{C} 1$ lateral masses $(\mathbf{J})$; distance between the medial border of the lateral mass and the midline on the right and left sides (K); height of the medial side of the lateral mass (L); height of the lateral side of the lateral mass $(\mathbf{M})$; width of the lateral mass $(\mathbf{N})$; height of the $\mathrm{C} 1$ anterior arch at $\mathrm{ML}(\mathbf{O})$.
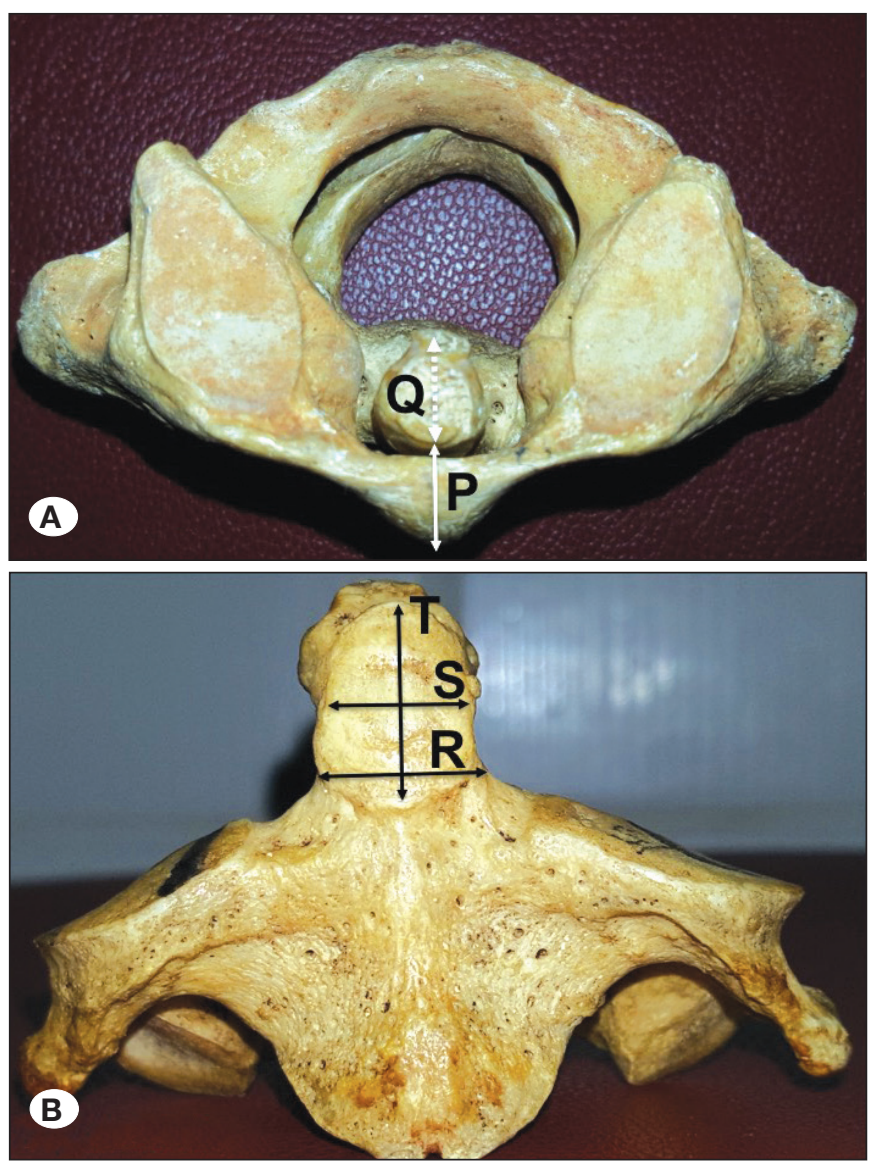

Figure 4: Ventromedian parameters related to $\mathrm{C} 1$ and $\mathrm{C} 2$ :

A) Superior aspect of C1-C2.

Distance between the ventral surface of the anterior arch and the ventral joint of the odontoid at $\mathrm{ML}(\mathbf{P})$; anteroposterior diameter of the odontoid base (dotted white line shows the base of the odontoid) (Q).

B) Ventral aspect of $\mathrm{C} 1-\mathrm{C} 2$

Horizontal diameter of the odontoid base (R); width of the odontoid-C1 joint (S); height of the odontoid-C1 joint (T). 


\section{RESULTS}

\section{Parameters Measured on Radiological Images of Cadavers}

The measurements of radiological anatomy parameters are listed in Table III. The distance between the anterior tubercle of $\mathrm{C} 1$ and the nasal bone (a) was $99.92 \pm 6.10 \mathrm{~mm}$, and the distance between the anterior tubercle of $\mathrm{C} 1$ and the superior incisors on the maxilla (b) was $76.65 \pm 8.46 \mathrm{~mm}$ (Figure 1A). The angles of TO (c) and TN approaches to C1 (d) were $32.67^{\circ} \pm 4.59^{\circ}$ and $32.00^{\circ} \pm 2.10^{\circ}$, respectively (Figure $1 \mathrm{~A}$ ). The distance between a horizontal line drawn parallel to the superior edge of the $\mathrm{C} 1$ anterior arch and the odontoid apex in a midsagittal CT image (e) was $1.63 \pm 1.06 \mathrm{~mm}$ (Figure 1B). The odontoid apex was located over the $\mathrm{C} 1$ superior edge of the $\mathrm{C} 1$ anterior arch in five cases, and at the same level in one case. The distance between a horizontal line drawn parallel to the inferior edge of the $\mathrm{C} 1$ anterior arch and the odontoid base in a midsagittal CT image (f) was $7.07 \pm 4.11 \mathrm{~mm}$ (Figure 1B). The odontoid base was located below the inferior edge of the $\mathrm{C} 1$ anterior arch in all cases.

\section{Parameters Measured on Cadavers During Surgical Dissection}

\section{Parameters related to approach}

The measurements of the parameters related to the approach are listed in Table IV. The mean distance between the C1 anterior tubercle and the external entrypoints (nares and superior incisors) was $96.16 \pm 8.07$ and $84.14 \pm 9.16 \mathrm{~mm}$, respectively. The mean distance between the pharyngeal tubercle and the inferior border of the C2 body was $50.86 \pm$ $5.33 \mathrm{~mm}$.

\section{Ventrolateral parameters related to lateral mass}

The measurements of the parameters related to the lateral mass are listed in Table $\mathrm{V}$. The mean distance between the medial borders of the right and left $\mathrm{C} 1$ lateral masses was $19.10 \pm 1.80 \mathrm{~mm}$. The mean distance between the medial border of the lateral mass and ML was $9.55 \pm 0.89 \mathrm{~mm}$.

The mean distance between the medial border of the lateral mass and $M L$ in the right and left sides $(M)$ were $9.43 \pm 0.88$

Table II: Parameters on Cadavers During Surgical Dissection

\section{A-Parameters related to approach}

The distance between nares and $\mathrm{C1}$ anterior tubercle (G) (Figure 2).

The distance between superior incisors and $\mathrm{C} 1$ anterior tubercle $(\mathrm{H})$ (Figure 2).

The distance between pharengeal tubercle and inferior border of C2 body (I) (Figure 2).

\section{B- Ventrolateral parameters related to lateral mass}

The distance between medial borders of right and left C1 lateral masses (J) (Figure 3).

The distance between medial border of lateral mass and midline in right and left sides (K) (Figure 3).

The height of medial side of lateral mass (L) (Figure 3).

The height of lateral side of lateral mass (M) (Figure 3).

The width of lateral mass (N) (Figure 3).

\section{C-Ventromedial parameters related to $\mathbf{C} 1$ and $\mathbf{C 2}$ :}

The height of $\mathrm{C} 1$ anterior arch at midline (O) (Figure 3).

The distance between ventral surface of anterior arch and ventral joint of odontoid on midline (P) (Figure 4A).

The anteroposterior diameter of odontoid on basis (Q) (Figure 4A).

The horizontal diameter of odontoid on basis (R) (Figure 4B).

The width of odontoid-C1 joint (S) (Figure 4B).

The height of odontoid-C1 joint (T) (Figure 4B).

Table III: Parameters Measured on Radiologicalimages of Cadavers

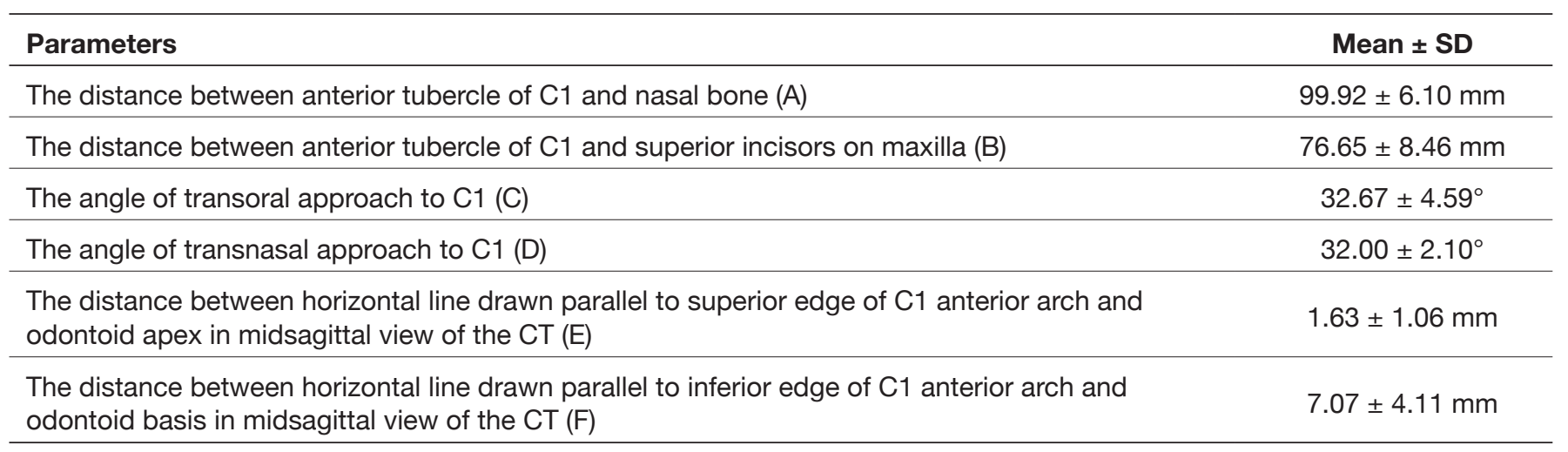


and $9.68 \pm 0.97 \mathrm{~mm}$, respectively. The mean heights of the medial and lateral sides of the C1 lateral mass were $15.56 \pm$ 1.57 and $22.71 \pm 1.57 \mathrm{~mm}$, respectively. The mean width of the lateral mass was $12.86 \pm 0.87 \mathrm{~mm}$.

\section{Ventromedian parameters related to C1 and C2}

The measurements of the ventromedian parameters related to C1-C2 are listed in Table VI. The mean height of the C1 anterior arch at ML was $13.89 \pm 2.48 \mathrm{~mm}$, and the distance between the ventral surface of the anterior arch and the ventral joint of the odontoid at ML was $6.43 \pm 1.29 \mathrm{~mm}$. The anteroposterior and mean horizontal diameters of theodontoid on its base were $12.12 \pm 0.38$ and $11.12 \pm 0.94 \mathrm{~mm}$, respectively. The mean width and height of the odontoid-C1 joint were $8.68 \pm$ 0.39 and $11.64 \pm 2.47 \mathrm{~mm}$, respectively.

\section{DISCUSSION}

Odontoidectomy with the TO and TN approaches are specific surgical procedures requiring knowledge about many aspects of the procedure. The preoperative planning and the actual surgical procedure are facilitated by careful acquisition of the required information about the anatomical parameters related to approach, C1-odontoid, lateral mass and morphometry of C1-C2. This study confirms that the TO approach provides a shorter distance to the surgical field when compared to the TN approach. This study reveals that the odontoid base is always located below the inferior edge of the $\mathrm{C} 1$ anterior arch, and in most cases, the odontoid apex is located over the superior edge of the $\mathrm{C} 1$ anterior arch (83.3\%). This study also demonstrates the availability of the anterior bony aspect of the C1-C2 complex for anterior stabilisation procedures.

\section{Parameters Related to Approach}

The angle of approach and distance from the entry point (TN or TO) to the surgical field are among the most important parameters related to approach which have an effect on the surgical procedure.

The angle of approach reflects the limits of the surgical field, particularly the superior limits. The angle of the TN approach is reported to be $28^{\circ}$ by Baird et al. (2), and $27.1^{\circ}$ by

Table IV: Parameters Related to Approach

\begin{tabular}{lc}
\hline Parameters & Mean \pm SD(mm) \\
\hline The distance between nares and C1 anterior tubercle $(\mathrm{G})$ & $96.16 \pm 8.07$ \\
\hline The distance between superior incisors and C1 anterior tubercle $(\mathrm{H})$ & $84.14 \pm 9.16$ \\
\hline The distance between pharengeal tubercle and inferior border of C2 body (I) & $50.86 \pm 5.33$ \\
\hline
\end{tabular}

Table V: Ventrolateral Parameters Related to Lateral Mass

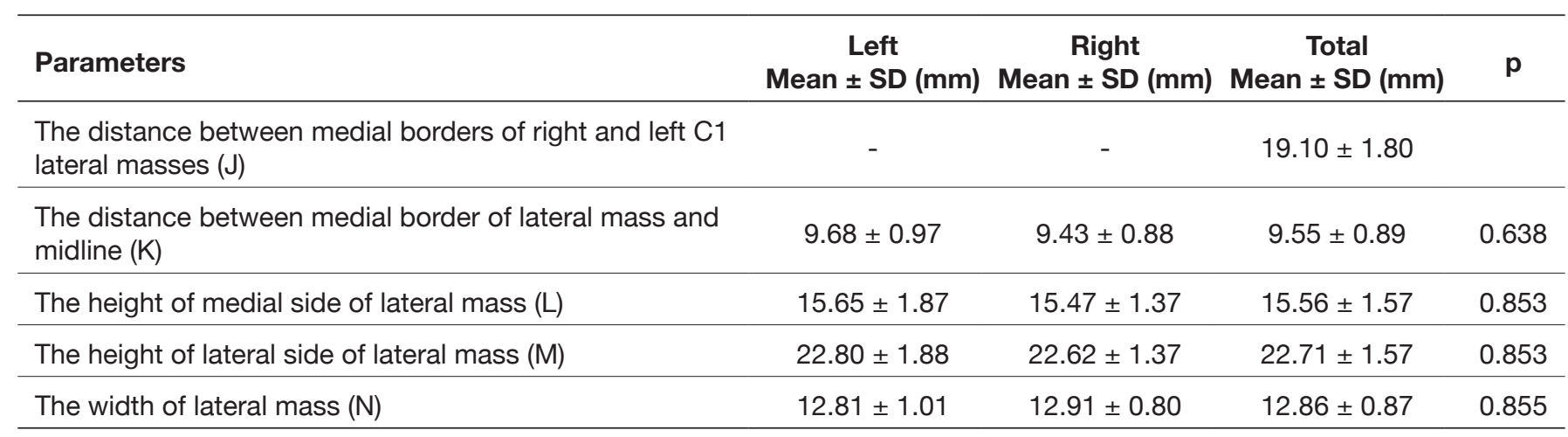

Table VI: Ventromedian Parameters Related to C1 and C2

\begin{tabular}{lr}
\hline Parameters & Mean \pm SD (mm) \\
\hline Height of C1 anterior arch at midline (O) & $13.89 \pm 2.48$ \\
\hline Distance between ventral surface of anterior arch and ventral joint of odontoid on midline (P) & $6.43 \pm 1.29$ \\
\hline The anteroposterior diameter of odontoid on base (Q) & $12.12 \pm 0.38$ \\
\hline The horizontal diameter of odontoid on base (R) & $11.12 \pm 0.94$ \\
\hline The width of odontoid-C1 joint (S) & $8.68 \pm 0.39$ \\
\hline The height of odontoid-C1 joint $(\mathrm{T})$ & $11.64 \pm 2.47$ \\
\hline
\end{tabular}


De Almeida et al. (6), and it is $32.00^{\circ} \pm 2.10^{\circ}$ in the current study. Our results are in agreement with previously published results. The angle to the surgical field may dictate the use of an endoscope. Preoperative measurement is helpful in predicting whether the use of an endoscope will be necessary.

The distance between the entry point and the surgical field is another important parameter to determinethe length of the approach and the length of the surgical instruments to be used during TO or TN odontoidectomy procedure. The distance between the superior incisors to the $\mathrm{C} 1$ anterior tubercle was reported to be $82.5 \pm 7.8 \mathrm{~mm}$ by Ai et al. (1), and $102 \mathrm{~mm}$ by Baird et al. (2). The distance for a TN approach was reported to be $94 \mathrm{~mm}$ by Baird et al. (2). Our study reveals that the distance between the anterior tubercle of $\mathrm{C} 1$ and the oral entry point is shorter than the distance between the anterior tubercle of $\mathrm{C} 1$ and the nasal entry point (76.65 \pm 8.46 vs. $99.92 \pm 6.10 \mathrm{~mm}$ in radiological images, and $84.14 \pm 9.16$ vs. $96.16 \pm 8.07 \mathrm{~mm}$ in anatomical measurements). However, this difference does not seem to be important in the era of microsurgery and endoscopic surgery.

\section{Parameters Related to $\mathbf{C 1}$ and the Odontoid Process}

$\mathrm{C} 1$ is located anterior to the odontoid process and it covers parts of the odontoid process. An odontoidectomy requires partial or total removal of the $\mathrm{C} 1$ anterior arch. Therefore, it is important to know the position of the $\mathrm{C} 1$ anterior arch with respect to both the odontoid apex and base. In all cases, this study shows that the odontoid base is located below the inferior edge of the $\mathrm{C} 1$ anterior arch. The distance between a horizontal line drawn parallel to the inferior edge of the $\mathrm{C} 1$ anterior arch and the odontoid base is $7.07 \pm 4.11 \mathrm{~mm}$ in radiological images.

Similarly, the distance between a horizontal line drawn parallel to the superior edge of the $\mathrm{C} 1$ anterior arch and the odontoid apex was reported to be $1.0 \mathrm{~mm}$ by Chan et al. (4), and is 1.63 $\pm 1.06 \mathrm{~mm}$ in the radiological images in our study. Our study also confirms that the odontoid apex is located over the C1 superior edge of the $\mathrm{C} 1$ anterior arch in five cases, and at the same level in one case.

These results suggest that cutting the odontoid base can be done with no additional procedure to the $\mathrm{C} 1$ anterior arch. However, partial or total removal of the $\mathrm{C} 1$ anterior arch is mandatory to remove all parts of the odontoid process, including the odontoid apex.

\section{Parameters Related to Lateral Mass}

The distance between the medial border of the lateral mass and $\mathrm{ML}$ is $9.55 \pm 0.89 \mathrm{~mm}$ in the current study. This distance was reported to be $7.8 \pm 1.0 \mathrm{~mm}$ by Ai et al. (1).

The distance between the medial borders of the right and left lateral mass is another parameter, reflecting the maximum width of the $\mathrm{C} 1$ anterior arch covering the odontoid process. In different series, the distances between the medial borders of the right and left lateral mass are $22.9 \pm 2.6(13), 18.5 \pm 2.4$ (10), and $16.1 \pm 1.5 \mathrm{~mm}$ (14). The differences in results may be explained by the measurement techniques employed. This distance is found to be $19.10 \pm 1.80 \mathrm{~mm}$ in the current study.
Notably, C1 anterior arch osteotomy, starting at ML, should not exceed more than 7-8 $\mathrm{mm}$ on each side.

The other parameters related to the lateral mass are the height and width of the $\mathrm{C} 1$ lateral mass. Information about these two parameters may be helpful during the $\mathrm{C} 1-\mathrm{C} 2$ plating procedure. This study reveals that the $\mathrm{C} 1$ lateral mass is wedge-shaped; therefore, the medial height is smaller than the lateral height. In our study, the height of the $\mathrm{C} 1$ lateral mass is $15.56 \pm 1.57 \mathrm{~mm}$ on the medial side and $22.71 \pm 1.57$ $\mathrm{mm}$ on the lateral side.The height of the medial side of the C1 lateral mass was reported to be $11.0 \pm 1.21$ (11), $7.28 \pm$ 1.75 (3), and $8.81 \pm 1.46 \mathrm{~mm}(5)$, in previous studies. Gupta reported that the mean height of the lateral mass (anterior) was $17.28 \pm 1.87 \mathrm{~mm}$ (9). Similarly, the height of the lateral side of the $\mathrm{C} 1$ lateral mass was found to be $18.01 \pm 2.33 \mathrm{~mm}$ by Christensen et al. (5), and between $17.4 \pm 1.65$ (minimum) and $22.0 \pm 1.89 \mathrm{~mm}$ (maximum) by Kandziora et al. (11).

In our study, the width of the C1 lateral mass is $12.86 \pm 0.87$ $\mathrm{mm}$. The same parameter was measured as $9.5 \pm 1.0 \mathrm{~mm}$ by Rocha et al. (13), and 14.1 $\pm 1.5 \mathrm{~mm}$ by Lu et al. (12).

\section{Ventromedian Parameters Related to $\mathbf{C} 1$ and C2}

The height of the $\mathrm{C} 1$ anterior arch at $\mathrm{ML}$ was reported to be $15.4 \pm 3.2 \mathrm{~mm}(7), 12.39 \pm 2.68 \mathrm{~mm}(5), 11.1 \pm 1.3 \mathrm{~mm}(12)$, $10.33 \pm 1.67 \mathrm{~mm}(8)$, and $10.8 \pm 1.21 \mathrm{~mm}(11)$, in previous studies. This parameter is $13.89 \pm 2.48 \mathrm{~mm}$ in the current study. The differences in the results of these published studies may be explained with methodological and material differences.

The distance between the ventral surface of the $\mathrm{C} 1$ anterior arch and the ventral joint of the odontoid at ML, a distance reflecting the depth required to reach the odontoid process, was reported to be $7.0 \pm 1.2 \mathrm{~mm}$ by Tun et al. (14). This distance is $6.43 \pm 1.29 \mathrm{~mm}$ in the current study.

The horizontal diameter of the odontoid base was reported to be $10.1 \pm 1.4 \mathrm{~mm}(14), 9.3 \pm 0.7 \mathrm{~mm}$ (12), and a minimum of $9.7 \pm 0.79 \mathrm{~mm}$ and a maximum of $10.8 \pm 0.84 \mathrm{~mm}(11)$, in previously published studies. It is $11.12 \pm 0.94 \mathrm{~mm}$ in the current study.

The anteroposterior diameter of the odontoid base was reported to be a minimum of $9.5 \pm 0.78 \mathrm{~mm}$ and a maximum of $10.8 \pm 0.84 \mathrm{~mm}(11)$, and $10.9 \pm 0.8 \mathrm{~mm}(12)$, in previous studies. This parameter is $12.12 \pm 0.38 \mathrm{~mm}$ in the current study.

The height and width of the odontoid-C1 joint may be important during the liberation of the odontoid process from its joint. According to Gosavi et al. (8), the width of the odontoid-C1 joint was $9.37 \pm 2.19 \mathrm{~mm}$, and the height of this joint was 8.91 $\pm 2.34 \mathrm{~mm}$. In the current study, the width and height of this joint are $8.68 \pm 0.39 \mathrm{~mm}$ and $11.64 \pm 2.47 \mathrm{~mm}$, respectively.

\section{- CONCLUSION}

A safe TO or TN odontoidectomy requires concise measurement and understanding about ventral $\mathrm{C} 1-\mathrm{C} 2$ relationships, particularly regarding distances of the odontoid, lateral mass and ML. 


\section{REFERENCES}

1. Ai F, Yin Q, Wang Z, Xia H, Chang Y, Wu Z, Liu J: Applied anatomy of transoral atlantoaxial reduction plate internal fixation. Spine 31(2):128-132, 2006

2. Baird CJ, Conway JE, Sciubba DM, Prevedello DM, QuiñonesHinojosa A, Kassam AB: Radiographic and anatomic base of endoscopic anterior craniocervical decompression: A comparison of endonasal, transoral, and transcervical approaches. Neurosurg 65:158-163, 2009

3. Blagg SE, Don ASD, Robertson PA: Anatomic determination of optimal entry point and direction for $\mathrm{C} 1$ lateral mass screw placement. J Spinal Disord Tech 22:233-239, 2009

4. Chan AK, Benet A, Ohya J, Zhang X, Vogel TD, Flis DW, El-Sayed IH, Mummaneni PV: The endoscopic transoral approach to the craniovertebral junction: An anatomical study with a clinical example. Neurosurg Focus 40(2):E11, 2016

5. Christensen DM, Eastlack RK, Lynch JJ, Yaszemski MJ, Currier BL: C1 anatomy and dimensions relative to lateral mass screw placement. Spine 32:844-848, 2007

6. De Almedia JR, Zanation AM, Snyderman $\mathrm{CH}$, Carrau RL, Prevedello DM, Gardner PA, Kassam AB: Defining the nasopalatine line: The limit for endonasal surgery of the spine. Laryngoscope 119: 239-244, 2009

7. Doherty BJ, Heggenes $\mathrm{MH}$ : The quantitative anatomy of the atlas. Spine 22: 2497-2500, 1994
8. Gosavi SN, Vatsalaswamy P: Morphometric study of the atlas vertebra using manual method. Malays Orthop J 6:18-20, 2012

9. Gupta T: Cadaveric morphometric anatomy of C-1 vertebra in relation to lateral mass screw placement. Surg Radiol Anat 30(7):589-593, 2008

10. Hu Y, Yang S, Xie H, He X, Xu R, Ma W, Feng J, Chen Q: The anatomic study on replacement of artificial atlanto-odontoid joint through transoral approach. J Huazhong Univ Sci Technolog Med Sci 28:327-332, 2008

11. Kandziora F, Schulze-Stahl N, Khodadadyan-Klostermann C, Schröder R, Mittmeier T: Screw placement in transoral atlantoaxial plating systems: An anatomical study. J Neurosurg Spine 95(1):80-87, 2001

12. Lu B, He XJ, Zhao CG, Li HP, Wang D: Artificial atlantoodontoid joint replacement through a transoral approach. Eur Spine J 18: 109-117, 2009

13. Rocha R, Safavi-Abbasi S, Reis C, Theodore N, Bambakidis N, de Oliveira E, Sonntag VK, Crawford NR: Working area, safety zones, and angles of approach for posterior C-1 lateral mass screw placement: A quantitative anatomical and morphometric evaluation. J Neurosurg Spine 6:247-254, 2007

14. Tun K, Kaptanoglu E, Cemil B, Karahan ST, Esmer AF, Elhan A: A neurosurgical view of anatomical evaluation of anterior C1C2 for safer transoral odontoidectomy. Eur Spine J 17: 853856, 2008 